\title{
CONF-950785--4
}

UCRL-JC-120320

PREPRINT

\section{Precise Thermal NDE for Quantifying Structural Damage}

\author{
N. K. Del Grande \\ P. F. Durbin
}

This paper was prepared for submittal to

22nd Review of Quantitative Nondestructive Evaluation

Seattle, WA

July 30-August 4, 1995

September 18, 1995

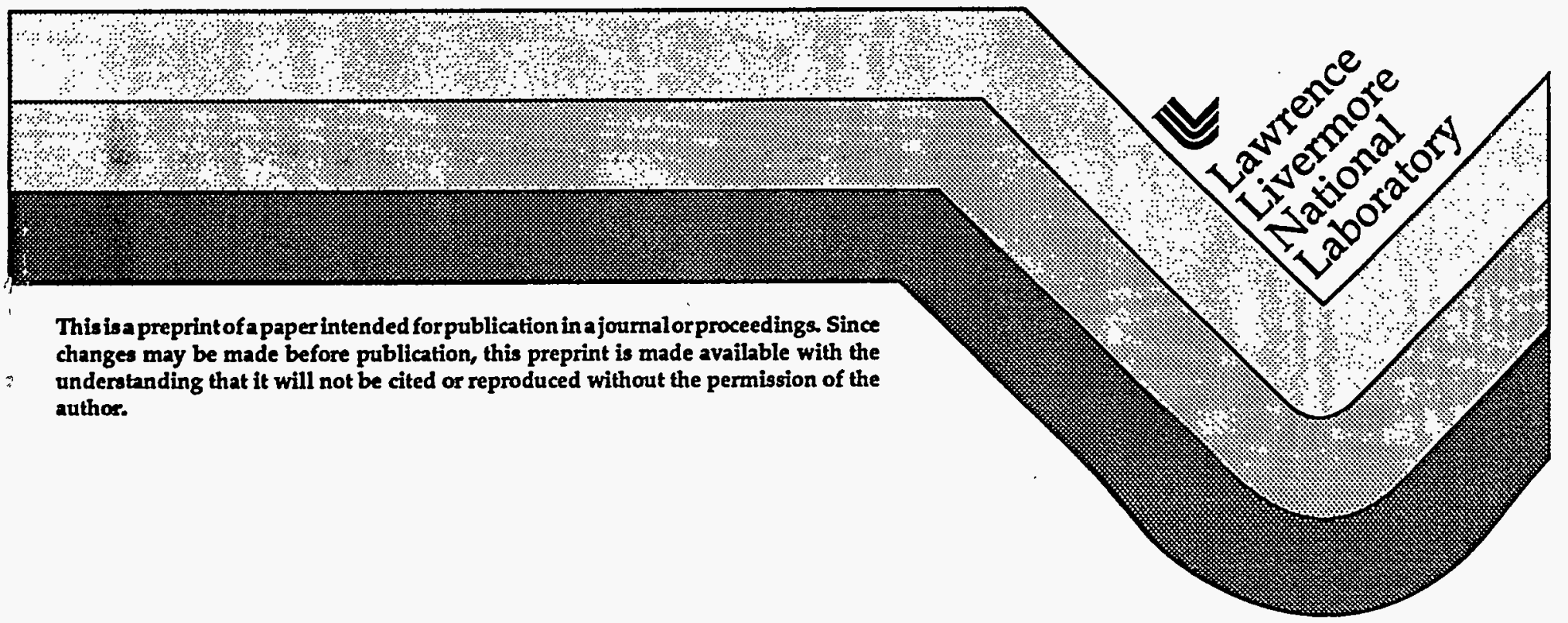




\section{DISCLAIMER}

\section{Portions of this document may be illegible in electronic image products. Images are produced from the best available original document.}




\title{
PRECISE THERMAL NDE FOR QUANTIFYING STRUCTURAL DAMAGE
}

\author{
Nancy K. Del Grande and Philip F. Durbin \\ Lawrence Livermore National Laboratory, \\ P.O. Box 808, Livermore CA 94551
}

\section{INTRODUCTION}

We have developed precise thermal NDE as a wide-area inspection tool to quantify structural damage within airframes and bridge decks. We used infrared cameras and image processing to produce precise temperature, thermal inertia, and cooling-rate maps of flashheated aircraft skins. These maps allowed us to distinguish major structural defects from minor flaws which do not warrant costly repairs. We quantified aircraft skin corrosion defects with metal losses as low as $5 \%$ with $3 \%$ overall uncertainty [1-6]. We proved the feasibility of precise thermal NDE to inspect naturally-heated asphalt-concrete bridge decks. To this end, we quantified structural damage within asphalt-concrete slabs by locating the sites, and determining the relative volumes, of concrete displacements from 2-inch deep and 4-inch deep synthetic delaminations in asphalt-concrete slabs [4-8].

Single-band infrared (SBIR) thermal imaging has been used to depict hidden defects without specifying the defect type, depth, or volume [9-13]. Typically, half of the defects specified with SBIR thermal imaging depict valid corrosion defects. The other half depict false corrosion defects resulting from minor fabrication flaws, e.g. skin ripples, paintthickness variations, repairs, excess sealants, and insulation wads, which do not warrant costly repairs. False detection of corrosion is costly. It results in unnecessary and destructive exploratory maintenance [14]. Dual-band infrared (DBIR) thermal imaging systems specify the defect type, depth and volume. DBIR imaging systems provide precise, emissivity-corrected temperature maps with a factor of ten improved signal-tonoise ratio compared to SBIR imaging systems. Precise DBR temperature, thermal inertia and cooling rate maps specify true corrosion defects and eliminate minor flaws [1-8].

\section{THEORY}

Our unique emissivity-corrected method for imaging anomalous structural heat flows uses ratios of two IR images at wavelength intervals: 3-5 $\mu \mathrm{m}$ and 8-12 $\mu \mathrm{m}$ to increase thermal sensitivity and decreases the adverse effects of surface-emissivity noise [15]. The image ratios are based on a power-series expansion of Planck's radiation law [16]. Near $288 \mathrm{~K}\left(15^{\circ} \mathrm{C}\right)$, the DBIR signal intensities vary as the emissivity multiplied by absolute temperature (T) to the power $(50 / \lambda)$, where $\lambda$ is the wavelength in microns, $\mu \mathrm{m}$. Signals centered near $5 \mu \mathrm{m}$ vary as the tenth power of temperature, whereas signals centered near $10 \mu \mathrm{m}$ vary as the fifth power of temperature. Equations 1 and 2 follow from the powerseries expansion of Planck's law. We use Eq. (1), to produce high-contrast temperature maps which depict both surface object sites and subsurface defect sites. We use Eq. (2), to produce emissivity-noise maps which depict only surface object sites.

$$
\begin{aligned}
& \left(\mathrm{T} / \mathrm{T}_{\mathrm{av}}\right)^{5}=\left(\mathrm{S} / \mathrm{S}_{\mathrm{av}}\right) /\left(\mathrm{L} / \mathrm{L}_{\mathrm{av}}\right) \text { and } \\
& \mathrm{E}=\left(\mathrm{L} / \mathrm{L}_{\mathrm{av}}\right)^{2} /\left(\mathrm{S} / \mathrm{S}_{\mathrm{av}}\right) .
\end{aligned}
$$


In Eqs (1) and (2), $S$ is the short-wavelength intensity signal, Sav is the average value of the pixels in $S, L$ is the long wavelength intensity signal, and $L$ av is the average value of the pixels in L. The high-contrast temperature maps based on Eq. 1 depict surface objects and hidden defects, whereas the emissivity-noise maps based on Eq. 2 depict only surface object sites. By combining the two maps, we clarify interpretation of deep structural defects by removing clutter from surface objects, stains, roughness, and compositional variations.

Additional procedures based on $\mathrm{Eq}$ (3) are needed to identify structural defects and remove the mask from subsurface features, e.g. ripples, patches, doublers, triplers, stiffeners, sealant globs and insulation wads, unrelated to structural defects. We developed thermal inertia maps to measure the bulk thermal properties of heat-stimulated structures. Thermal inertia maps have been used previously for other applications. $[14,15]$ We solve the heat transfer equation for a thick target with an instantaneous surface heat flux: [16]

$$
T(x, t)=\frac{q}{\sqrt{4 \pi k \rho c t}} \exp \left(-\frac{x^{2}}{4 \alpha t}\right)
$$

In Eq. 3, $\mathrm{T}$ is temperature, $\mathrm{x}$ is the distance from the surface, $\mathrm{k}$ is thermal conductivity, $\rho$ is density, $c$ is heat capacity, $\alpha$ is thermal diffusivity, $t$ is time and $q$ is the surface heat flux. Using the semi-infinite solid approximation, the surface temperature of Eq. 3 is proportional to the inverse square root of time. In practice, we map the fuselage composite thermal inertia, $(\mathrm{kpc})^{1 / 2}$, based on the inverse slope of the surface temperature versus the inverse square root of time. Thermal inertia maps measure the bulk thermal properties of multi-layered materials. Thermal inertia patterns change dynamically with duration and time lapse after the heat flash and the defect depth, type and volume in the host structure.

\section{HEAT-STIMULATED METAL AIRFRAME DEFECT MAPS}

Temperature, timegram and thermal inertia maps clarify interpretation of defects and quantify the percent metal loss from corrosion within a Boeing 727 airframe. See Figures 1 and 2. The temperature maps at the top of Fig. 1 and the top right of Fig. 2 refer to aircraft skin temperatures which were recorded at $0.43 \mathrm{~s}$ after the heat flash. The temperature map at the top left of Fig. 2 was recorded at $0.12 \mathrm{~s}$ after the heat flash.

Aircraft skin temperature maps show surface temperature increases (warming) at sites where the skin thicknesses decreases. Using ultrasonic thickness gauges, we measured skin thickness variations from .107 inches, at the upper left, to .070 inches, at the upper middle, and to .063 inches at the upper right, for chemically milled sites in Fig. 2.

We used six reference standards, to show a typical $1^{\circ} \mathrm{C}$ temperature rise at 0.43 seconds after the flash corresponded to a $12.5 \%$ metal loss for skins ranging in total thickness from .030 to 0.125 inches. The gray scale has a range of $5^{\circ} \mathrm{C}$ with the warmer sites appearing in lighter shades of gray.

At the bottom of Fig. 1, timegram cooling-rate maps show the cooling-rate signatures at .0 to. 16 seconds after the heat flash. The vertical axis is used to scale time, relative to the heat flash, which increases downward for linescan profiles across the acraft skin. Metal thinning, from chemical milling, corrosion, or other causes, has a characteristic band-like cooling-rate signature on the timegram map. Thinner skins reach higher peak temperatures, take longer to cool to the ambient temperature, and appear as lighter shades of gray.

At the bottom of Fig. 2, thermal inertia maps show how the near surface structures, when compared to the deeper structures, have varying physical properties. Thermal inertia is the square root of the target conductivity, density, and heat capacity. It is a measure of the resistance to temperature change for bulk materials within the target. At early times from 0.1 to $0.4 \mathrm{~s}$ at the bottom left, the thermal inertia maps depict lighter corrosion sites with lower thermal inertia at the faying edge of the outer skin which was riveted to a stiffener. At late times from 0.4 to $0.7 \mathrm{~s}$ at the bottom right, the thermal inertia maps depict lighter corrosion sites within the deeper and thicker stiffener. 


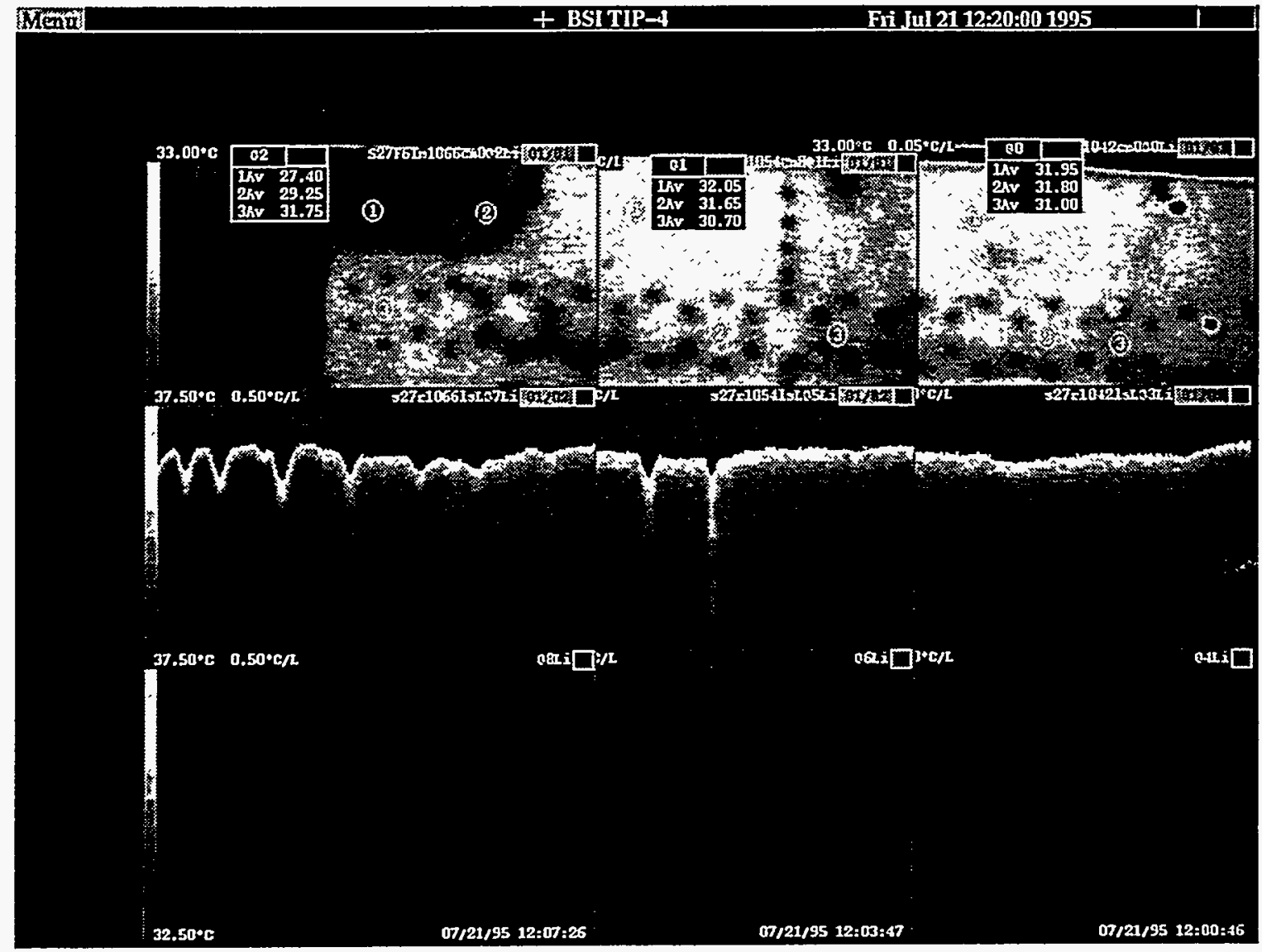

Fig. 1. Aircraft skin temperature map, above, and timegram cooling rate map below.
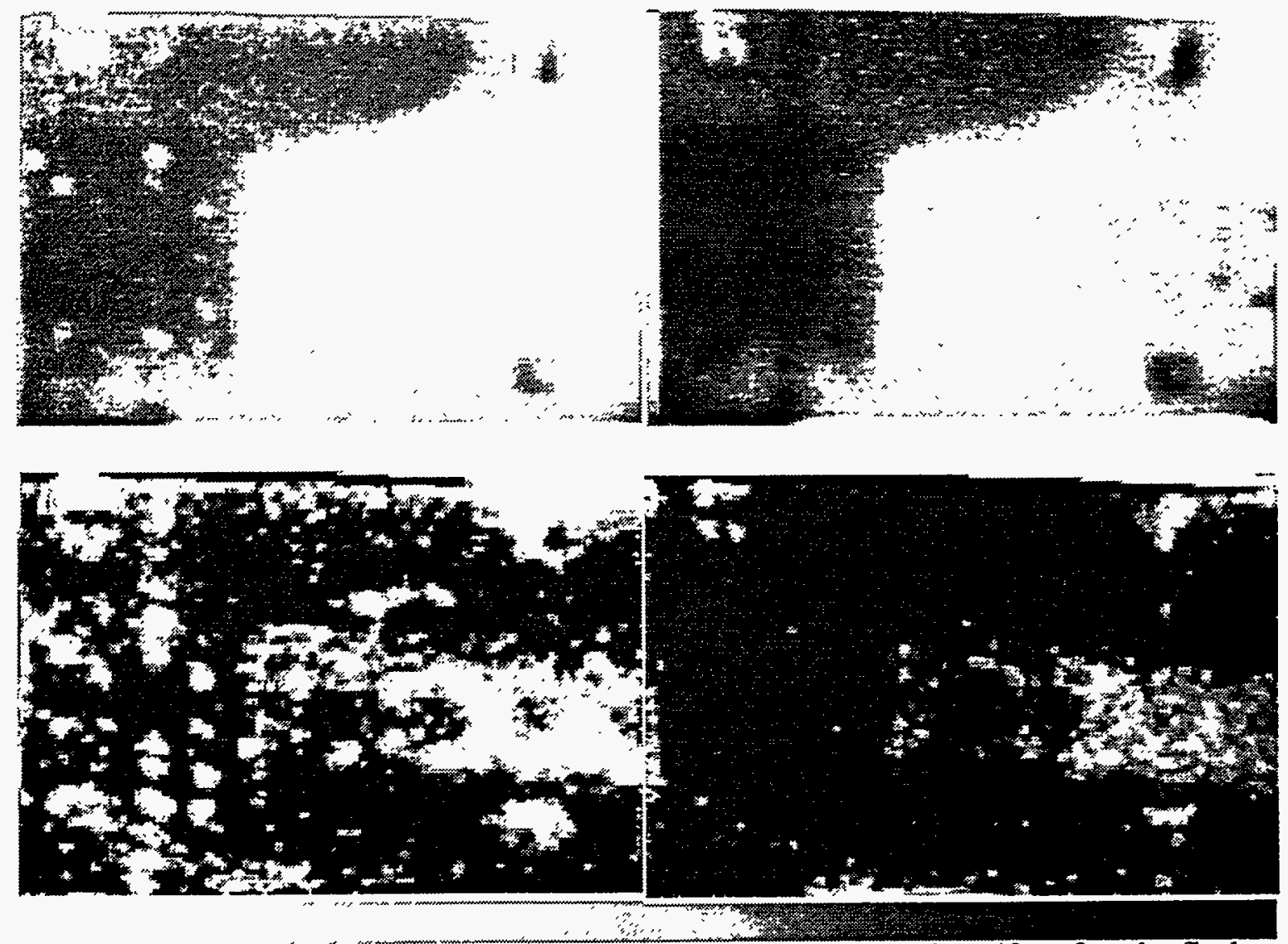

Fig. 2. Top left to right: aircraft skin temperature maps at $.12 \mathrm{~s}$ and at $.43 \mathrm{~s}$ after the flash. Bottom left to right: Early-time thermal inertia map of outer skin and late-time thermal inertia map of deep stiffener. Note corrosion-thinned skins are lighter than normal. 
We developed algorithms which produced co-registered images of emissivity-corrected temperature, thermal inertia and timegram cooling-rate maps. Using these maps, we inferred the defect type, site, size, material-loss and depth. The heat flow anomalies generated by a $4.2 \mathrm{~ms}$ heat flash have thermal signatures which characterize the target physical properties, such as temperature, cooling rate, and thermal inertia. These thermal signatures differ at sites where the multi-layered structures are defective.

Timegrams record the dynamic response of flash-heated linescan profiles taken across the Boeing 727 airframe. The timegram has time increasing downward, along the vertical axis, the target profile positioned along the horizontal axis, and the cooling-rate signature which appeared as lighter shades of gray at sites which had $10 \%$ corrosion loss. Our algorithms produced thermal, timegram cooling-rate, and thermal inertia maps which clarify interpretation of structural defects and eliminate false (corrosion-loss) defects. Using pulsed-thermal imaging, we characterized structural defects by their location, depth and the degree to which their cooling-rate signatures differed from ambient for the host-material.

We developed algorithms to remove factors which obscure proper identification of airframe corrosion-loss defects. Firstly, typical flashlamp sources produce uneven heat patterns. We correct for this with filters generated by our algorithms which remove the uneven heat source effects for a uniform thickness reference standard. Secondly, emissivity noise results from surface clutter, e.g.tape marks, dirt, uneven paint, stains, roughness variations which mask structural defects. Both clutter and defect sites appear on uncorrected thermal maps. Only defect sites appear on corrected thermal maps. Thirdly, interpreting airframe bulges as "pillowing" from expansion of corrosion by-products is subjective. Skin bulges vary only slightly for other defect types such as excess sealants, paint thickness variations and skin ripples. For better defect definition and interpretability, we characterized defects by their temperature, timegram cooling rate and thermal inertia responses based on the six reference standards with thicknesses from .030 to .125 inches.

\section{NATURALLY-HEATED CONCRETE SLAB DEFECT MAPS}

We proved the feasibility of concrete bridge deck inspections using emissivity-corrected temperature maps to image the sites of synthetic delaminations from styrofoam implants inserted in concrete and asphalt-concrete slabs. We mounted the DBIR cameras on an outdoor tower platform to test the optics we would use on a moving-vehicle system which would not impede the flow of traffic. We determined the optimal times and conditions to image and detect structural defects in concrete and asphalt-concrete slabs. We discovered a strong correlation between DBIR implant-site daytime minus nighttime temperature signals: $0.7^{\circ} \mathrm{C}$ to $3.2^{\circ} \mathrm{C}$, and their respective styrofoam implant volumes: 1 to 10 cubic inches. Thus, the larger delaminations should be characterized by stronger temperature signals.

1. At the left of the diagram in Fig. 3, are the relative sites of deep styrofoam implants: 1-5, and concrete surface objects: A - E, while at the right of the diagram in Fig. 3, are the sites of styrofoam implants: $1-6$, and asphalt-concrete surface objects: A-E. The asphaltconcrete slab had a 2 -inch asphalt surface layer. Thermistors located at $\mathrm{X}, \mathrm{Y}$ and $\mathrm{Z}$ recorded above-ambient midday and below-ambient nighttime temperature signals.

Using DBIR image ratios, e.g., from DBIR cameras which scan at infrared wavelengths of 3-5 $\mu \mathrm{m}$ and $8-12 \mu \mathrm{m}$, we enhanced temperature contrast and removed the mask from surface-emissivity noise. We studied the effects of surface contamination and compositional variations. We placed various objects along the perimeter of the slabs, such as sand, gravel, grease stains, oil spots, metal objects, and lane markers. We developed algorithms to distinguish surface object sites from hidden defect sites.

Enhanced temperature-contrast and emissivity-noise maps clarified interpretation of the concrete compositional differences near the slab center, in Fig. 4. There was a molecularstretch resonance, for the 8-12 $\mu \mathrm{m} \mathbb{R}$ band, where the slab did not emit IR radiation like an ideal blackbody surface. This produced a non-thermal pattern on the temperature map. Since this pattern was also on the emissivity-noise map, it depicted a surface compositional effect, unlike a heat flow anomaly generated by one of the thin styrofoam implants. 


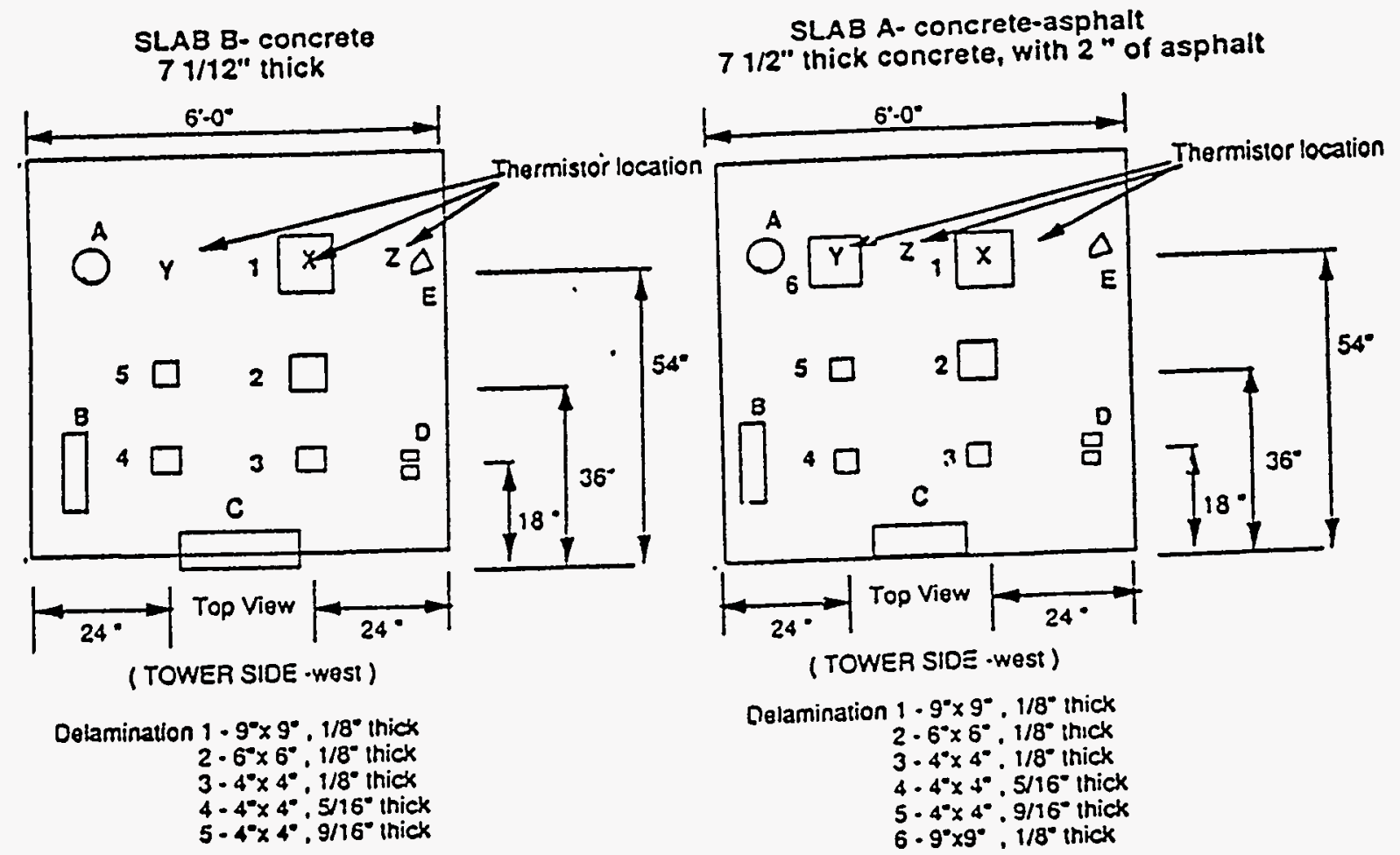

Figure 3. Diagram of concrete slab, at left, and asphalt-concrete slab, at right, depicting surface object and hidden defect sites. Delaminations. result from corroded steel reinforcement bars which are typically placed 2 in. beneath the concrete surface where we placed five implants at sites $1-5$ and one implant at the asphalt-concrete interface at site 6 .
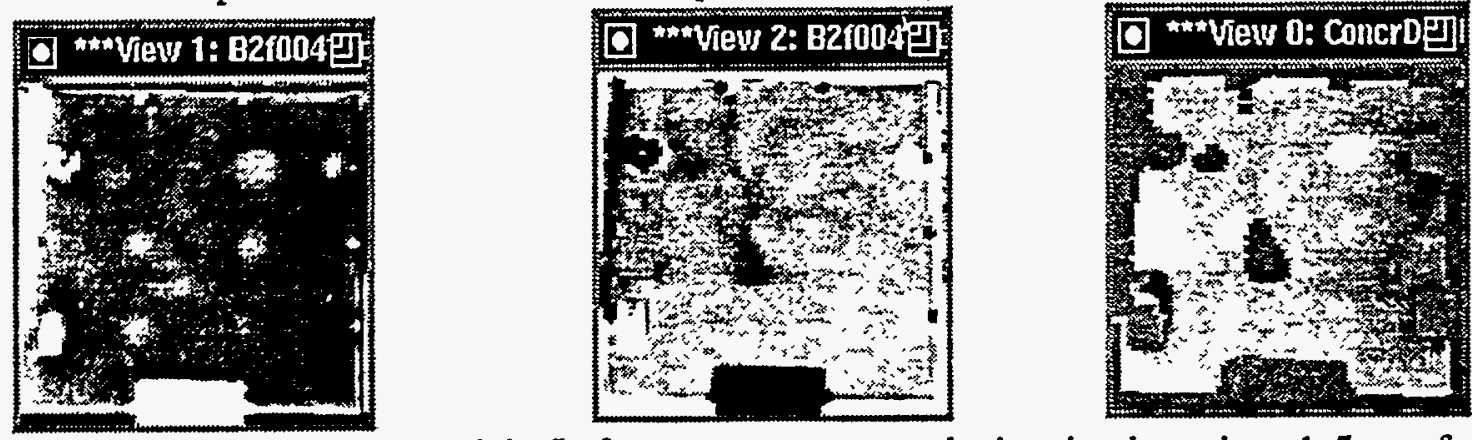

Figure 4. Daytime concrete slab. Left: temperature map depicts implant sites 1-5, surface object sites A-E, and compositional variations beneath slab center, of Fig. 3. Center: emissivity-noise map depicts all but implant sites 1-5. Right: defect site map depicts only implant sites $1-5$ by subtracted the emissivity-noise sites from the temperature map sites.
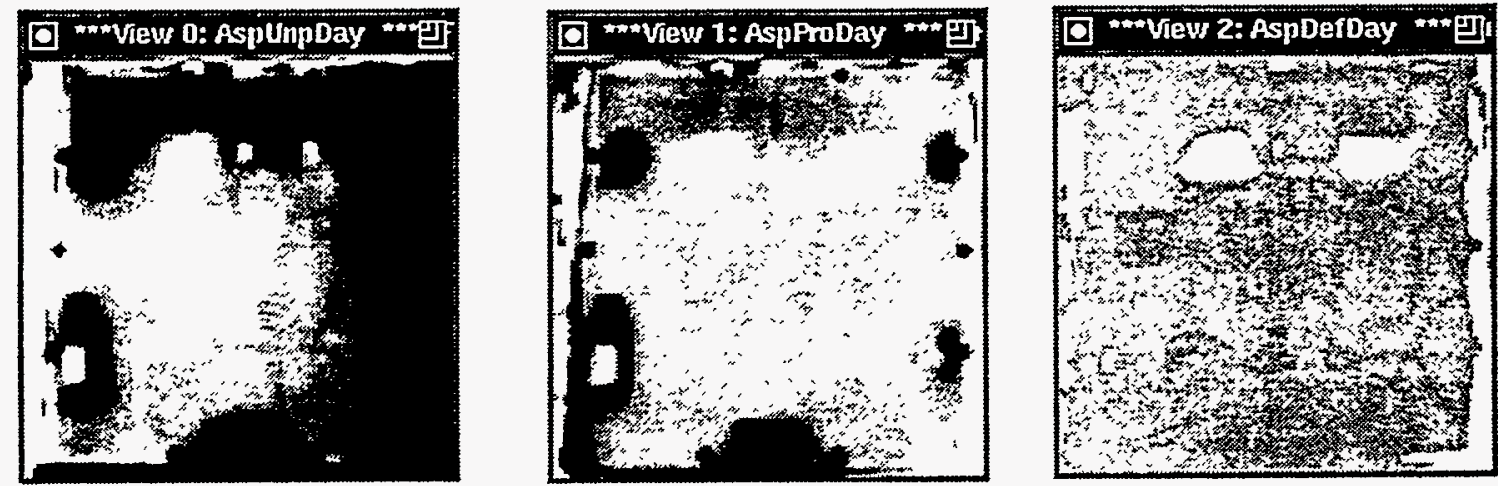

Figure 5. Left: daytime asphalt-concrete temperature map showing the temperature gradient for an unevenly compacted asphalt layer. Center: processed temperature map which clearly depicts the 9-inch on-a-side square styrofoam implant sites at 1 and 6 , right side of Fig. 3; Right: Defect site map depicting only the 9-inch implant sites: 1 and 6, right side of Fig. 3 . 
Density variations over the 2 -inch layer of unevenly-compacted asphalt, produced a $2{ }^{\circ} \mathrm{C}$ temperature-gradient across the unprocessed temperature map at the left side of Figure 5. We used special image processing filters to remove this mask. The processed temperature map clearly depicted the deeper and weaker $0.6^{\circ} \mathrm{C}$ temperature signals from implants which were 4 inches deep, at the top right corner, $3.8^{\circ} \mathrm{C}$ temperature signals from implants which were 2 inches deep, at the top left corner of the asphalt-concrete slab in Figure 5.

\section{SUMMARY AND CONCLUSION}

We demonstrated a fast, wide-area, precise thermal NDE imaging system to quantify aircraft corrosion damage, such as percent metal loss, above a threshold of $5 \%$ with $3 \%$ overall uncertainties. The DBIR precise thermal imaging and detection method has been used successfully to characterize defect types, and their respective depths, in aircraft skins, and multi-layered composite materials used for wing patches, doublers and stiffeners. This precise thermal NDE inspection tool has long-term potential benefits to evaluate the structural integrity of airframes, pipelines and waste containers.

We proved the feasibility of the DBIR thermal NDE imaging system to inspect concrete and asphalt-concrete bridge decks. As a logical extension to the successful feasibility study, we plan to inspect a concrete bridge deck from a moving vehicle to quantify the volumetric damage within the deck and the percent of the deck which has subsurface delaminations. Potential near-term benefits are in-service monitoring from a moving vehicle to inspect the structural integrity of the bridge deck. This would help prioritize the repair schedule for a reported 200,000 bridge decks in the United States which need substantive repairs. Potential long-term benefits are affordable, and reliable, rehabilitation for bridge decks.

\section{ACKNOWLEDGMENTS}

This work was performed by LLNL under the auspices of DOE contract number W-7405-ENG-48. We acknowledge support from the FAA Aging Aircraft Non-Destructive Inspection R\&D Program, Interagency Agreement DTFA03-92-A-00007 and Federal Highway Administration FHWA Order Number DTFH61-93-Y-00145. We are grateful for the loan of the Bales Scientific Inc. uniform flashlamp heating source, the Rockwell 0.040inch and 0.125 -inch graded-thickness reference standards developed by Steve James, the F-15 corroded wing box which we used as a reference standard from Owen Manning at Northrop, and the reference panels from Jeff Thompson at Boeing. We acknowledge the helpful technical discussions, ultrasonic thickness-gauge measurements and support of the Boeing Commercial Airplane Group.

\section{REFERENCES}

1. N. K. Del Grande and P. F. Durbin, "Mapping hidden aircraft defects with dual-band infrared computed tomography" in Proceedings of SPIE Conference 2455: Nondestructive Evaluation of Aging Aircraft, Airports, Aerospace Hardware, and Materials, Ed. Tobey Cordell, Oakland CA, pp. 82-93, June 6-8, 1995.

2. Nancy K. Del Grande, Philip F. Durbin and Michael R. Gorvad, "Applications Of Infrared Computed Tomography" in Nondestructive Evaluation Thrust Area Report FY94. Engineering Research Development and Technology, Ed. Harry E. Martz, UCRL-ID119059, pp. 7.7-7.13, Feb. 1995.

3. N. K. Del Grande, P. F. Durbin, K. W. Dolan, P. F. Durbin, M. R. Gorvad and A. B. Shapiro, "Dynamic thermal tomography for nondestructive inspection of aging aircraft" in Proceedings of SPIE Conference 2001: Nondestructive Inspection of Aging Aircraft, Ed. Michael T. Valley, Nancy K. Del Grande and Albert S. Kobayashi, San Diego CA, pp. 6677, July, 1993. 
4. N. K. Del Grande and P. F. Durbin, and P. F. Durbin, "Stimulated dual-band infrared computed tomography: a tool to inspect the aging infrastructure" in Proceedings of SPIE Conference 2552: Infrared Technology XXI,Ed. B. F. Andreson and M. S. Scholl, San Diego CA, pp. 292-301, July 9-13, 1995.

5. N. K. Del Grande and Philip F. Durbin, "Multi-use applications of dual-band infrared (DBIR) thermal imaging for detecting structural defects" in Proceedings of SPIE Conference 2217: Aerial Surveillance Sensing Including Obscured and Underground Object Detection, Ed. Ivan Cindrich, Nancy K. Del Grande, Sankaran Gowrinathan, Peter Johnson and James F. Shanley, Orlando FL, pp. 107-116, Apr. 1994.

6. N. K. Del Grande and P. F. Durbin, "Dual-Band Infrared Imaging to Detect Corrosion Damage Within Airframes and Concrete Structures", in Proceedings of SPIE Thermosense XVI, International Conference on Thermal Sensing and Imaging and Diagnostic Applications, Ed. John Snell, Orlando FL, pp. 202-209, Apr. 1994.

7. N. K. Del Grande and P. F. Durbin, "Using emissivity-corrected thermal maps to locate deep structural defects in concrete bridge decks" in Proceedings of SPIE Conference 2456: Nondestructive Evaluation of Aging Bridges and Highways, Ed. Steve Chase, Oakland CA, pp. 250-261, June 6-8, 1995.

8. Philip Durbin and Nancy Del Grande, "Dual-band Infrared Imaging For Concrete Bridge Deck Inspection", Proceedings of Structural Materials Technology-An NDT Conference, Atlantic City NJ, pp. 17-20, Feb. 1994.

9. J. W. M. Spicer, W. D. Kerns, L. C. Aamodt, R. Osiander and J. C. Murphy, "TimeResolved Infrared Radiometry (TRIR) using a Focalplane Array for Characterizations of Hidden Corrosion", Proceedings of SPIE Conference 1933: Thermosense XV. Ed. Lee R. Allen, Orlando FL p. 148, 1993.

10. L. D. Favro, P. K. Kuo, R. L. Thomas, T. Ahmed and Y. X. Wang, "Thermal wave imaging of corrosion and disbonds in aircraft structures" in Proceedings of SPIE Conference 2001: Nondestructive Inspection of Aging Aircraft Ed. Michael T. Valley, Nancy K. Del Grande and Albert S. Kobayashi, San Diego CA, 1993.

11. John J. Selman and J. Ted Miller, "Evaluation of a prototype thermal wave imaging system for nondestructive evaluation of composite and aluminum aerospace structures", Proceedings of SPIE Conference 1933: Thermosense XV Ed. Lee R. Allen, Orlando FL p. $178,1993$.

12. Hazari I. Syed, and K. Elliott Cramer, "Corrosion Detection in Aircraft Skin", Proceedings of SPIE Conference 1933: Thermosense XV. Ed. Lee R. Allen, Orlando FL p. $160,1993$.

13. V. P. Vavilov, and X. Maldague, "Dynamic thermal tomography: a new promise in the IR thermography of solids", Proceedings of SPIE Conference 1682: Thermosense X1V. Ed. Jan K. Eklund, Orlando FL p. 194, 1992.

14. John Alcott, "An Investigation of Nondestructive Inspection of Nondestructive Inspection Equipment: Detecting Hidden Corrosion on USAF Aircraft" in Materials Evaluation. American Society for Nondestructive Testing, Jan., 1994.

15. N. K. Del Grande , K. W. Dolan, P. F. Durbin and D. E. Perkins, "EmissivityCorrected Infrared Method for Imaging Anomalous Structural Heat Flows", US Patent No. 5,444,241 (Aug. 22, 1995).

16. L. A. LeSchack, and N. K. Del Grande, "A Dual-Wavelength Thermal Infrared Scanner As A Potential Airborne Geophysical Exploration Tool", Geophysics 41, p. 1318, (1976). 
17. E. G. Grinzato, C. Bressan, P. G. Bison, A. Mazzoldi, P. Baggio, C. Bonacina, "Evaluation of moisture content in porous material by dynamic energy balance", in Proceedings of SPIE Conference 1682: Thermosense XIV Ed. Jan K. Eklund, Orlando FL p. 213, 1992.

18. Ph. M. Delpech, D. M. Boscher, F. Lepoutre, A. A. Deom and D. L. Balageas, "Quantitative nondestructive evaluation of carbon-carbon composites by pulsed infrared thermography", in Review of Progress in Quantitative Nondestructive Evaluation, 12B. Ed. by Donald O. Thompson and Dale E. Chimenti, Plenum Press, New York and London, p. 1297, 1993.

19. H. S. Carslaw and J. C. Jaeger, Conduction of Heat in Solids, 2nd Edition, Oxford Univ. Pr., London, pp. 101, 112 and 259, 1980. 